\title{
Enrollment Quota Control, Elite Selection and Access to Education
}

\author{
in Rural China
}

\author{
Luan Zhao \\ School of Economics and Management, Tsinghua University, Beijing 100084, China \\ E-mail: zhaoluan@mails.tsinghua.edu.cn
}

\begin{abstract}
In China, the access to education is determined by not only student's demand for schooling, but also the allocation of educational resources and the schools' selection of candidate students. Based on the data obtained from the rural life level and rural social assistance household surveys in four provinces in 2005, the demand-identified bivariate probit model is adopted to identify whether rural youths have the demand for schooling, distinguish between the students' demand for schooling and the selection of schools, and open out the influence and function of family and social backgrounds on rural youths to acquire the education above junior high school. The empirical research shows that both the deficiency of demand for schooling and the enrollment quota control are important obstacles to restrain the access to education, and the demand for schooling and the elite selection of school all obviously incline to the families and peoples with predominant social backgrounds. The policy implication of this research is that it is imperative under the situation to adopt measures such as improving the demand for schooling of the disadvantaged families and further loosening the enrollment quota control, but the former is more important.
\end{abstract}

Keywords: Access to education, Demand for schooling, Estimation of demand-identified bivariate probit model

\section{Introduction}

Though the access to education is generally regarded as the important channel to reduce the intergenerational transmission of poverty and promote the flow from the lower class to the upper class of the society, but the researches aiming at many countries indicated that the education opportunity obviously inclined to the group with predominant family or social background, which also means that in many economic objects, the education has been one important mechanism to maintain the privilege status of the superior class in the society, and continue the inequity of the society and the economy (Li, Chunling, 2003). In China, the significant influences of family economy, and education and class background on the access of education have been extensively validated in many researches (Guo, Congbin, Min, Weifang, 2006 \& Tao, Hong, Yang, Dongping, 2007 \& Liu, Jingming, 2008 \& Hou, Longlong, Li, Fengliang, Zheng, Qinhua, 2008). Some researches (Li, Chunling, 2003 \& Li, Yu, 2006, Liu, Jingming, 2006 \& Hao, Dahai, 2007 \& Wu, 2007) also paid attention to the influences of the special social backgrounds such as the system transfer of China and the social structure on the access to education. One noticeable problem is the access to education of children in rural regions. Because the unbalance of rural and urban development in China, and education opportunities of urban and rural children are largely different (Fan, Mingcheng, 2008), and if the expanded trend of the educational unbalance between villages and cities continues, it may be the important hidden trouble to maintain even expand the gap between villages and cities (Qain and Smyth, 2008).

Therefore, to develop and promote the access to education in rural regions has been regarded as an imperative task for the government of China. However, the efforts that the government develops the educational opportunities will not always obtain anticipated effects. For example, after 1950s, some countries adopted the measures to expand the educational scale in the primary education and the secondary education, but some researches indicated that the expansion of educational scale had not significantly improved the equality of educational opportunity (Shavit, Arum and Gamoran, 2007). Raftery and Hout (1993) put forward the hypothesis of "Maximally Maintained Inequality", and they thought that the expansion of education scale would not certainly improve the equality of education opportunity except that the education demand of the group with predominant social state had been achieved certain saturation, or else, those parents with higher social and economic state would always try to acquire added enrollment chances, so the enrollment status of the disadvantaged groups would be improved limitedly. This instance could be found in the enrollment expansion of Chinese colleges. The researches aiming at the expansion of Chinese higher education scale in the near future indicated that the increase of the total amount of Chinese higher education opportunity had not obviously reduce the educational disparities (Liu, Jingming, 2006 \& Hao, Dahai, 2007), and many problems such as reduced education quality and descended rates of return to education induced by the enrollment expansion would first strike the demand for schooling of the disadvantaged groups, and the final result would even deteriorate, not improve the access to education of the disadvantaged groups. 
Accordingly, to effectively develop the education opportunity of the disadvantaged groups, the government must deeply analyze the obstacles that the disadvantaged groups can not acquire the education, and in this way, the government will have a definite object in view. One key problem is whether the disadvantaged groups have the demand for schooling. In China, various levels of education are not students' free selection, and except for the demand of schooling, the enrollment is also determined by the selection of schools and the distribution of education resources. Both the secondary education and the higher education in china adopt strict selection mechanism of entrance examination, and the ability selection mechanism based on the achievements of examination is the main mode to distribute scare education resources (Wang, 2008). If rural families also have the demand for schooling, but lose the enrollment opportunities only because of the limited education resources, the expansion of education scale will help the disadvantaged groups to acquire the education. However, if rural families would not accept the investment of human capitals at all, the measures that the government expands the education scale will not be effective, and it is the essential method for the government to enhance the drive that the disadvantaged groups acquire the education.

By the special data of questionnaires about survey of the rural life level and the social assistant households, when effectively identifying the causes that rural children don't enter a higher school, a new demand-identified bivariate probit model is adopted to identify whether rural youths have the demand for schooling, distinguish between the students' demand for schooling and the selection of schools, and open out the influence and function of family and social backgrounds on rural youths to acquire the education above junior high school.

The structure of this article can be described as follows. The second chapter introduces the adopted data and the selection of measurement model. The third chapter introduces the demand for schooling in various educational stages and the descriptive statistical characters with satisfied degree. The fourth chapter explains the explanation variables adopted in the research about the access to education. The fifth chapter studies the bivariate probit model simultaneously considering education demand and supply, and opens out the advantages of the bivariate probit model estimation comparing with simple probit model estimation. The sixth chapter further analyzes and opens out the time-sequence character of the demand for schooling and its satisfied state. The seventh chapter summarizes the research conclusions and the policy implications of this article.

\section{Data and measurement model selection}

The data in this article are from the rural life level and social assistance household surveys in four provinces organized by the China Ministry of Civil Affairs in 2005. By the mode of grading random sampling, 1600 rural households were surveyed in four provinces including Zhejiang, Fujian, Guangxi and Gansu. The database recorded the income, payout, education experiences and working state of each family member in detail. The most character of this database is to offer the survey of causes that investigators have not entered into a higher school, which needs to distinguish the obstacles of education access respectively induced by the demand factors and the supply factors and more deeply understand the influences and the function mechanism of the family and society backgrounds on the access to education.

One two-stage model is used to describe students' process entering a higher school. In the first stage, rural youths would select whether they would accept the higher education according to their own and family backgrounds, and the application for higher school is one symbol which means that students have the demand for schooling. In the second stage, schools select the applicants to determine the distribution of education resources.

The dummy variables $y_{\mathrm{D}}$ and $y_{5}$ are respectively used to denote students' demand for schooling and the selection of school. $y_{\mathrm{D}}=1$ denotes rural youths have the demand for schooling, and $y_{\mathrm{D}}=0$ denotes rural youths would not enter a higher school, and $y_{5}=1$ denotes school admits the student through the selection, and $y_{5}=0$ denotes that the school has not admit the student. Only when $v_{D}=1$ and $y_{8}=1$, rural youths can be observed to acquire higher education. In addition, $y_{\mathrm{D}}^{*}$ and $y_{\mathrm{E}}^{*}$ respectively are used to denote the hidden variables influencing rural youths' demand for schooling and the selection of the school, and they are non-observable, and the relationship between them with $y_{y}$ and $y_{S}$ is

$$
\begin{aligned}
& f y_{D}^{*}=\beta_{D}^{t} x_{D}+\varepsilon_{D} r \quad \text { if } y_{D}^{*}>\theta y_{D}=1 \text {, or } y_{D}=0
\end{aligned}
$$

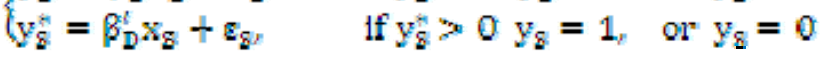

$$
\begin{aligned}
& \mathrm{E}\left[\varepsilon_{\mathrm{g}}\right]=\mathrm{E}\left[\varepsilon_{\mathrm{D}}\right]=0_{r} \quad \operatorname{Var}\left[\varepsilon_{\mathrm{g}}\right]=\operatorname{Var}\left[\varepsilon_{\mathrm{g}}\right]=1, \quad \operatorname{cov}\left[\varepsilon_{\mathrm{g},} \varepsilon_{\mathrm{D}}\right]=\rho
\end{aligned}
$$

\subsection{Estimation of single-variable probit model}

Generally speaking, the maximum information which could be observed is whether rural youths would enter a higher school. The present research is mainly to apply the single-variable probit model to study the influencing factor of the rural youths' probability entering a higher school. Suppose that $y$ is the variable denoting whether students could enter a higher school, and it is the interaction result of $y_{\mathrm{D}}$ and $y_{S}$, and only when rural youths have the demand for 
schooling $\left(y_{\mathrm{D}}=1\right)$ and the school would admit the student $\left(y_{8}=1\right)$, rural youths could enter a higher school favorably.

$$
\left\{\begin{array}{rr}
y=1, & \text { if } \mathrm{y}_{\mathrm{s}}=1 \text { and } \mathrm{y}_{\mathrm{D}}=1 \\
\mathrm{y}=0_{r} & \text { otherwise }
\end{array}\right.
$$

If the problem that schools select students doesn't exist, entering a higher school is students' independent choice, and the access to education is only determined by students' demand for schooling. Here, it is a better selection to use the single-variable probit model to study the access to education. But when rural students' demand for schooling and the selection of the school exert the function simultaneously and the function mechanisms are different, if certain factor simultaneously impacts students' demand for schooling or the selection of the school, the single-variable analysis model can only be used to obtain general conclusion, which can not distinguish the influences of students' demand and the supply of the school. And even if certain factor only influences students' education demand, the single-variable analysis model can only be used to obtain inefficient evaluation value, because in the single-variable probit model estimation, the problem whether students enter a higher school can only be identified, and those explained variables such as the students have the demand for schooling but have not passed the entrance examination and the students have not the demand for schooling, which will obviously induce the deviation of the estimation result.

\subsection{Estimation of educational demand-identified bivariate probit model}

If rural youths' demand for schooling YD can be identified by the mode of questionnaire survey, and this excessive information can significantly improve the validity of the estimated result, and more abundant estimated result can be obtained. The bivariate probit model is estimated by the following bivariate equation.

$$
\left\{\begin{array}{l}
\operatorname{Pr}\left(y_{D}=1\right)=\operatorname{Pr}\left(y_{D}^{*}>0\right)=\operatorname{Pr}\left(\varepsilon_{D}>-\beta_{D}^{t} x_{D}\right) \\
\operatorname{Pr}\left(y_{\Omega}=1 \mid y_{D}=1\right)=\operatorname{Pr}\left(y_{\Omega}^{*}>0\right)=\operatorname{Pr}\left(\varepsilon_{\Sigma}>-\beta_{\Omega}^{t} x_{\Omega}\right)
\end{array}\right.
$$

The first equation is to estimate the influencing factor of students' demand for schooling, and it is called as the demand equation. After identifying rural youths' demand for schooling, the second equation will estimate the influencing factor of the selection of the school for those students have the demand for schooling, and it is called as the supply equation.

The establishment of the bivariate probit model is because that only when $y_{D}=1$, students will apply for the entrance to the school, and the information about $y_{S}$ can be observed, and when $y_{D}=0$, the information about $y_{S}$ will not be observed.

The maximum likelihood method (MLE) is adopted to estimate the above bivariate probit equations, and the logarithm likelihood function can be denoted as

$$
\begin{aligned}
& \ln \mathrm{L}\left(\beta_{\mathrm{g}}, \beta_{\mathrm{D}}, \rho\right)=\sum_{i=1}^{\mathrm{N}}\left(\mathrm{y}_{\mathrm{D}} \mathrm{y}_{\mathrm{g}} \ln \Phi_{1}\left(\beta_{\mathrm{D}}^{t} \mathrm{x}_{\mathrm{D}}, \beta_{\mathrm{g}}^{t} \mathrm{x}_{\mathrm{g}} \rho\right)+\left(1-\mathrm{y}_{\mathrm{D}}\right) \ln \Phi_{2}\left(-\beta_{\mathrm{D}}^{t} \mathrm{x}_{\mathrm{D}}\right)\right.
\end{aligned}
$$

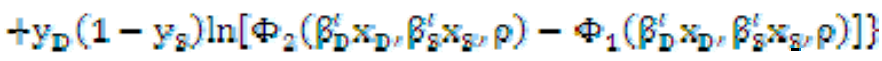

In the bivariate probit model, $\Phi_{1}\left({ }_{0}\right)$ and $\left.\Phi_{2}()_{0}\right)$ are supposed as the normal distribution functions.

Comparing with the estimation of the single-variable probit model, the education demand-identified bivariate probit model could identify and more largely utilize the information that the samples in which students have not entered a higher school. It makes decomposing of the influences of two factors including students' demand for schooling and the selection of the school feasibly, and it can also remedy the deviation of the estimation of the single-variable probit model, so the more effective measurement estimation result can be obtained.

\section{Descriptive statistical characters of the demand for schooling and its satisfied degree}

It is easy to identify whether rural youths could acquire higher education, but rural youths' demand for schooling is difficult to identify. If rural youths finally participate in the education of certain stage, so they certainly have the demand for the education in this stage. But for the students who have not entered a higher school, rural youths' demand for schooling can not be directly observed. These problems will usually be encountered when studying the credit acquirement. The usual solution is to adopt the direct elicitation methodology, and the measure of questionnaire survey is used to identify the credit demand, for example, Huang Zuhui, Liu Xichuan and Cheng, Enjiang (2009) directly identified the excessive information of credit demand by the questionnaire survey to study the credit acquirement of China. In this article, the survey data just offer the item about the causes that the students have not entered a higher school, so it can identify whether these students have the demand for schooling.

Concretely speaking, the causes which influence rural youths to accept the subsequent education can be approximately divided into two sorts. The first sort includes individual or family factors, and as seen in Table 1, "couldn't afford to the 
school charge", "would not go to school themselves" and "lacking in labor force in their families" are main individual or family causes to restrain the access to education in various stages entering a higher school, and these factors influence individuals' favors to accept education or the economic cost and the opportunity cost to accept education. The second sort comes from the special enrollment quota control in China, and because of limited education resources, China establishes strict entrance examination selection system in various classes of education, and distributes the education opportunities by the selection. In this survey, the primary scholars, the junior high school students, and the senior high school students who have not entered a higher school because they didn't pass the entrance examination respectively occupy $7.51 \%, 27.61 \%$ and $38.12 \%$. It is obvious to see that in the higher education stage, the function of the education quota control is more obvious.

To participate in the entrance examination can be regarded as the symbol whether students would enter a higher school and have the demand for schooling, so those students who have not passed the entrance examination of higher school are the appliers who have the demand for schooling but are eliminated by the school. Table 2 shows the statistical result of students' demand for schooling and the relative satisfied state in various education stages entering a higher school. In addition, because higher education stage have stronger education quota control degree, the satisfied degree of the demand for schooling is lower, and because of two above causes, the access of the education in higher schooling stage is worse.

\section{Setup and explanation of variables}

The former literatures studying the access to education and the educational disparities mainly considered the influences of the individual characters of the sex and nationality, the parents' education background, the parents' occupation (class) status, the family economy and the family structure on the access to education for children. Except for above factors, aiming at the special background of rural youths' access to education, the explained variables such as "parents do works for others far from hometown" and "whether there are long-term sickened members in the family" are added in this article. Following analysis can indicate that above factors can simultaneously influence rural youths' demand for schooling and the selection of the school. The factor of the provincial higher education opportunity is also considered in this article, and it can only influence rural youths' demand for schooling after graduating from the junior high school, but will not influence the selection of the school for students.

Parents' education degree has positive influence on their children's access to various classes of education. The family with higher parents' education degree has higher education anticipation for their children, and their children will also accept this concept certainly, at the same time, parents with higher education degree have the ability to implement tutorship and explanation for their children's learning (Li, Yu, 2006), so their children's demand for schooling will be enhanced, and the possibility that their children are selected by the school will be enhanced also. In this research, parents' education degree is the education term inquired in the questionnaires. For the samples without the data of the education term, the corresponding education degree will be converted into the education term. Parents' education were surveyed in 2005, and parents' education level will not change largely, so the survey data can basically represent parents' real educated degree when their children make the decision to enter a higher school from the junior high school at 16 years old.

The family income is the important factor to influence children's access of education. On the one hand, many students can not afford the schooling or think a lot of the work income than the demand of education because of the limitation of the fluidity, or they will more consider reduce the family burden as soon as quickly, and give up the chance to enter a higher school. At this time, the family income will influence rural youths' demand for schooling. On the other hand, rich families can enhance students' learning ability by purchasing counseling books, employing family education, or offering more convenient conditions for students, and with the development of the education marketilization in China, the channels bartering economic resources for education change increase more and more, such as sponsoring enrollment, and pay students in the double-track system, and the family income will indirectly influence the selection of the school for students.

It is very difficult to study the influences of the family income on the access of education as viewed from the empirical data. First, because of the limitation of the data, the real family income of 16 years old youths when they make the decision to enter the junior high school, and the survey data only could show the income information of the family members in the late of 2005. Second, even if the real family income is known, the family incomes of the youths in different education stages accepting the education of the junior high school can not be compared, and the quick variance of the family incomes induced by the quick economy development of China also pricks up the comparison unbalance of the data. According to above situations and the limitation of data, the compromise scheme is to acquire the ranking of family incomes, not the absolute amount. The parents' non-agricultural incomes in 2004 are selected to study the ranking of family rankings because first, rural households have the character to make decisions by the unit of household, and parents' incomes will undoubtedly occupy the large proportion in the children's education payout, second, the family structure in the late of 2005 may be largely different with the family structure when 16 years' old children make 
the decision to enter the junior high school, so it is the better selection to only consider parents' incomes, third, the non-agricultural incomes would more represent the ranking of the income abilities, and the difference of non-agricultural incomes is the main factor to induce the income difference in rural regions. To deal with the problem that the family incomes in different stages can not be compared, for the samples making the decision to enter the junior high school in different stages, the parents' non-agricultural incomes in 2004 are respectively ranked. The concrete operation method is that the households which parents' non-agricultural incomes are not zero are divided into four groups according to rural youths' ages in 2005 , i.e. below 20 years old, from 20 years old to 25 years old, from 25 years old to 30 years old, and above 30 years old, and each group is divided into the low subgroup, the middle subgroup and the high subgroup according to parents' non-agricultural incomes in 2004. Because parents' non-agricultural abilities in different ages are not even to change, so this treatment method can not completely reflect the income ranking when 16 years' old children make the decision to enter the junior higher school, but it can effectively reduce the problems that the data can not be compared.

Parents' predominant occupation and class background will influence children's education anticipation and the acceptance ability of education by influencing the cultural capital of family (Liu, Jingming, 2008). Considering the sample character of rural regions, for parents' occupation division, the class of farmer is a individual sort, and the principles of the party and administration departments, and the enterprises and professional technology employees are combined as one sort, and these people represent the predominant class in the rural regions, and others occupations and the samples which occupations can not be known are regarded as other classes. The parents' occupation backgrounds in the survey of 2005 basically can represent parents' occupation background when their 16 years old children make the decision to enter the junior high school.

After Becker (1960) put forward the quantity-quality trade-off theory, i.e. families would balance the quantity and quality of their children's education, many empirical researches have validated the negative correlation relationship between the family scale and the education quality, and the research aiming at China could be seen in Li's article (Li, et al., 2008). When family has several children, parents' energy will certainly be dispersed to look after them, and the family income has to support these children's education simultaneously, which will influence children's demand for schooling and learning ability, and the possibility that they are selected by the school. In the survey data, the information of the family scale can be obtained directly.

With the transformation course of China, it is very universal for rural labor forces to flow to urban regions. And parents' migrant working will largely influence rural youths' access to education. De Brauw and Gile's research (De Brauw and Gile, 2006) showed that good migrant opportunity may make rural youths to select the present income, but influence the will to enter the junior high school. Parents' migrant working obviously will make children to have better migrant opportunity and channels. In addition, the problem about unattended children has been extensively concerned by the society in recent years. Those parents who often work far from hometown have not the ability to look after their children's life and learning, so children's educated ability and the will of schooling will be influenced. The proportion that rural youths' parents had worked far from the hometown above three months is used to represent the variable that parents worked far from hometown in this article.

The influence of sickened family members on youths' access to education is still rare. Especially in the rural regions that the medical guarantee has not been spread, long-term sickened member in the family represents very expensive medical payout, which will make rural youths to more easily give up the opportunity entering a higher school because of the limitation of the fluidity, and accordingly influence their will to enter a high school, but the sickened family members basically will not influence the selection of the school for students. The survey data in 2005 can be used to inquire whether the family has the patient with over three month's chronic disease when the 16 years old rural youth makes the decision to enter the junior high school.

The influence of the provincial higher education opportunity on rural youths' demand for the schooling of junior higher school is also reviewed in this article. Comparing with other developing countries, the higher education return of China is higher, but the return of the senior higher education is very low (Zhang et al, 2005). When the entrance opportunities of higher education increase, the incomes that rural youths continue to enter a higher school will be enhanced, and the will of rural youths graduating from the junior high school to participate in the subsequent education will be enhanced. However, the provincial higher education opportunities basically will not influence the selection of the school for students. Li Lifeng's method and data (2007) are adopted to reflect the difference of the provincial higher education opportunities in different years, i.e. dividing the proportion of the amount of the students graduating from the senior high school each year in the whole country by the proportion of the various provincial enrollment amount of higher education in the whole country, and obtaining the index of entrance opportunity.

\section{Empirical analysis result of bivariate probit model estimation}

\subsection{Educational demand-identified bivariate probit model estimation}

By the estimation method in the Chapter 3, the education demand-identified bivariate probit model is adopted to respectively study the influences factors of the access to education from the junior high school to the senior high school, 
and from the senior high school to college, and the estimation result is seen in Table 3. For example, when the problem whether students have the demand for schooling and acquire the education of the senior high school in the stage from the junior high school to the senior high school, the control group is the samples who has completed the learning of the junior high school and has not accepted the subsequent education.

In the stage from the junior high school to the senior high school, whether the demand for schooling or whether the selection of the school will obviously incline to those students with predominant family and society backgrounds. The influences of most explanation variables including parents' educated term, family non-agricultural income, father's occupation, family scale, long-term sickened family members and provincial higher education opportunity on rural youths' demand for schooling and the selection of the school are all consistent with the theoretical anticipation. The bivariate probit model allows comparing with the influences of students' demand for schooling and the selection of the school on the access to education by comparing with the demand equation and the supply equation from the significance and the coefficients of the variables. For example, comparing with children's demand for schooling, parents' educated term exerts larger function for children's learning ability, and the family children scale will largely influence rural youths' demand for schooling.

But in the stage from the senior high school to college, the family and society backgrounds basically have not significant influences on the demand for schooling and the selection of the school, which is significantly consistent with the researches in others countries, i.e. the family and society backgrounds would largely influence the stage of lower education. At the same time, that is related with the sample characters of poor rural households, and small part of students entering the senior high school have belonged to the families with predominant family and society backgrounds, and whether these students could enter colleges is mainly determined by their individual efforts or abilities, not relatively better family backgrounds.

\subsection{Comparison with the estimation result of single-variable probit model}

To explain the meanings and advantages of the education demand-identified bivariate probit model estimation, the estimation result of the single-variable probit model can be compared with the measurement result. The explained variable in the single-variable estimation model is whether rural youths enter a higher school in certain stage. Comparing with the single-variable probit model or the Logit model, the estimation advantages of the education demand-identified bivariate probit model are mainly reflected in following aspects.

First, the bivariate probit model estimation can acquire more information, i.e. acquiring the influencing factors such as the demand for schooling and the selection of the school simultaneously, and identify and decompose the different influences of two sorts of factor on the access to education by comparing the estimation significances and coefficients of the supply equation and the supply equation.

Second, especially when certain factor can only influence students' demand for schooling and the selection of the school, the single equation model will easily produce the deviation of the estimation result, so the effective measurement result is hard to obtain. For example, in the stage from the junior high school to the senior high school, the bivariate probit model estimation result shows that the provincial higher education opportunity would significantly positively influence rural youths' demand for schooling, but the single-variable probit model estimation result could not indicated the significant influence of this variable. The estimation result of bivariate probit model indicates that the family children scale would significantly negatively influence rural youths' demand for schooling, and the significant influence of the selection of the school has not been found, but the single-variable probit model estimation could directly show the insignificant influencing result.

\section{Time-sequence characters of the demand for schooling and its satisfied state}

It is very necessary to review the time-sequence characters of rural youths' demand for schooling and the enrollment quota control in the system variance of China, which can not only open out the basic trends of the access to education in various educational stages, but review whether the obstacles of the access to education in different term from the supply layer or the demand layer, and point out the time-sequence change trend of these obstacles. The same term of birth group method is adopted in the research, i.e. matching the information of the access to education of corresponding years in different education stages according to the education characters such as youths above 16 years old enter the senior high school and youths above 19 years old enter the college in rural regions to implement the statistics.

First, the time-sequence characters of the stage from the junior high school to the senior high school are studied. In Figure 1, the entrance rate from the junior high school to the senior high school continually increase in recent tens years. The increase is mainly because the satisfied degree entering the senior high school is continually enhanced, i.e. the control of enrollment quota continually is loosed, not the enhancement of the demand for schooling. The proportion of the junior high school students with the demand for the schooling of the senior high school is always kept in about $60 \%$, but the satisfied degree of the demand of entering the senior high school had been ascended from about 50\% in 1990 to above $80 \%$ after 2000 , which make the proportion of the junior high school students who can accept the education of 
the senior high school to approach 30\% in 1990 to above $50 \%$ after 2000 .

Comparing with that, the access to education of the stage from the senior high school to college has not obvious time-sequence trend. The proportion of the senior high school students who have the demand for entering the college is basically in $50 \% \sim 60 \%$, and the satisfied degree of the demand for schooling has been ascended in recent years, and at present, about $50 \%$ students' demand for schooling can be satisfied.

\section{Conclusions and policy implication}

Based on the data obtained from the rural life level and rural social assistance household surveys organized by the China Ministry of Civil Affairs in four provinces in 2005, the demand-identified bivariate probit model is adopted to identify whether rural youths have the demand for schooling, distinguish between the students' demand for schooling and the selection of schools, and open out the influence and function of family and social backgrounds on rural youths to acquire the education above junior high school.

As viewed from the empirical data, both the deficiency of the demand for schooling and the entrance examination failures with the will of schooling are important obstacles to restrain the access to education. The problem of the enrollment quota control in the stage from the junior high school to the senior high school has been basically solved, and the bottleneck to improve the access to education is to improve the demand for entering the senior high school. And in the stage from the senior high school to the college, large space to further eliminate the enrollment quota control still exists, but to improve the demand from the senior high school to the college is the key factor. Therefore, except for expanding the enrollment scale, the government is necessary to adopt further measures to try to enhance students' will of schooling. The causes that students have not enter a high school show that the most important factor restraining the demand for schooling is that students can not afford the schooling charges, therefore, the government should urgently constitute the schooling charge and life allowance assistant polices aiming at poor students in rural regions to face the fluidity limitation in poor farmers' education investment when the education costs continually ascend.

\section{References}

A. E. Raftery and M. Hout. (1993). Maximally Maintained Inequality: Expansion, Reform, and Opportunity in Irish Education (1921-1975). Sociology of Education. No.66(1). P.41-62. M.

Becker, Gary S. (1960). An Economic Analysis of Fertility. Demographic and Economic Change in Developed Countries. Gary. Becker, ed. Princeton: Princeton University Press.

De Brauw Alan and John Gile. (2008). Migrant opportunity and the Educational Attainment of Youth in Rural China. Policy Research Working Paper 4526. World Bank Development Research Group (February) Washington DC.

Fan, Mingcheng. (2008). Research on the Urban-rural Difference in the Chance of Receiving Higher Education in China. Education Science. No.24(1).

Guo, Congbin \& Min, Weifang. (2006). Influence of Family Economy and Cultural Capital on the Access to Family Education Chance. Journal of Higher Education. No.11.

Hao, Dahai. (2007). Research of Education Stratification in Chinese Cities. Social Sciences in China. No.6.

Hongbin Li, Junsen Zhang, Yi Zhu. (2008). The Quantity-Quality tradeoff of Children in a Developing Country: Identification using Chinese Twins. Demography.

Hou, Longlong, Li, Fengliang \& Zheng, Qinhua. (2008). Influence of Family Background on the Quantity and Quality Attainment of Higher Education As Viewed from Social Stratification. Journal of Higher Education. No.29(10).

Huang, Zuhui, Liu, Xichuan \& Cheng, Enjiang. (2009). Experience Explanation of Low Participation Degree of Farmers' Normal Credit Market in Poor Regions. Economic Research Journal. No.5.

Li, Chunling. (2003). Society and Politics Variance and Education Chance Inequality: Influence of Family Background and System Factor on the Access to Education. Social Sciences in China. No.3.

Li, Lifeng. (2007). Regional Justice Research in the Enrollment Exam of Chinese Colleges. Wuhan: Central China Normal University Press. Oct. of 2007.

Liu, Jingming. (2006). Expansion of Higher Education in China and Inequality in Entrance Opportunities: 1978-2003. Society. No.3.

Liu, Jingming. (2008). Opportunity Inequality and Changes in the Basic Education Domain of China. Social Sciences in China. No.5.

Li, Yu. (2006). System Variance and the Generation Mechanism of Education Inequality: Chinese Urban Families' Access to Education (1996-2003). Social Sciences in China. No.4.

Tao, Hong \& Yang, Dongping. (2007). An Empirical Analysis of the Relationship between Educational Achievement 
and Family Background of High School Students. Tsinghua Journal of Education. No.28(1).

Wang Li. (2008). Education inequality in China: Problems of policies on access to higher education. Journal of Asian Public Policy. Vol.1. No.1. March. P.115-123.

Xiaogang Wu. (2007). Economic Transition, School Expansion, and Educational Inequality in China, 1990-2000. Working Paper, Population Studies Center Research Report 07-627.

Xiaolei Qain and Russell Smyth. (2008). Measuring regional inequality of education in china: widening coast-inland gap or widening rural-urban gap. Journal of international development. No.20. P.132-144.

Yossi Shavit, Richard Arum and Adam Gamoran. (2007). Expansion, Differentiation and Stratification in Higher Education: A Comparative Study of 15 Countries. Working paper.

Zhang, Junsen, Yaohui Zhao, Albert Park and Xiaoqing Song. (2005). Economic Returns to Schooling in Urban China, 1988 to 2001. Journal of Comparative Economics. No.33. P.730-752.

Table 1. Survey result of causes that surveyed students don't enter a higher school

\begin{tabular}{|l|c|c|c|}
\hline & $\begin{array}{l}\text { Don't enter a higher } \\
\text { school after } \\
\text { graduating from } \\
\text { elementary school }\end{array}$ & $\begin{array}{l}\text { Don't enter a higher } \\
\text { school after } \\
\text { graduating from } \\
\text { junior high school }\end{array}$ & $\begin{array}{l}\text { Don't enter a higher } \\
\text { school after } \\
\text { graduating from } \\
\text { senior high school }\end{array}$ \\
\hline $\begin{array}{l}\text { Didn't pass the enrollment exam of } \\
\text { higher school }\end{array}$ & 7.51 & 27.61 & 38.12 \\
\hline Couldn't afford to the school charge & 61.05 & 42.28 & 20.22 \\
\hline Would not go to school themselves & 22.21 & 25.10 & 21.30 \\
\hline $\begin{array}{l}\text { Lacking in labor force in their } \\
\text { families }\end{array}$ & 2.84 & 2.51 & 2.93 \\
\hline Sickened or disabled & 2.33 & 0.45 & 2.16 \\
\hline Need to look after family members & 1.12 & 0.31 & 0.00 \\
\hline $\begin{array}{l}\text { Parents didn't allow them to go to } \\
\text { higher school }\end{array}$ & 0.61 & 0.00 & 0.15 \\
\hline Too far from the nearest school & 0.00 & 1.52 & 14.66 \\
\hline Other causes & 2.33 & & \\
\hline
\end{tabular}

Table 2. Students' demand for schooling and its satisfied state

\begin{tabular}{|l|l|l|l|}
\hline & $\begin{array}{l}\text { From elementary } \\
\text { school to junior high } \\
\text { school }\end{array}$ & $\begin{array}{l}\text { From junior high } \\
\text { school to senior high } \\
\text { school }\end{array}$ & $\begin{array}{l}\text { From senior high } \\
\text { school to college }\end{array}$ \\
\hline Without the demand for schooling & 15.24 & 42.53 & 46.36 \\
\hline $\begin{array}{l}\text { With the demand for schooling but } \\
\text { didn't pass the enrollment exam }\end{array}$ & 1.25 & 16.29 & 28.55 \\
\hline $\begin{array}{l}\text { With the demand for schooling and } \\
\text { passing the enrollment exam }\end{array}$ & 83.51 & 41.18 & 25.09 \\
\hline $\begin{array}{l}\text { Satisfied degree of the demand for } \\
\text { schooling }\end{array}$ & 98.52 & 71.66 & 46.77 \\
\hline
\end{tabular}


Table 3. Estimation result of educational demand-identified bivariate probit model

\begin{tabular}{|c|c|c|c|c|}
\hline & \multicolumn{2}{|c|}{$\begin{array}{c}\text { Stage from junior high school to senior } \\
\text { high school }\end{array}$} & \multicolumn{2}{|c|}{$\begin{array}{l}\text { Stage from senior high school to } \\
\text { college }\end{array}$} \\
\hline & Supply equation & Demand equation & Supply equation & Demand equation \\
\hline \multirow{2}{*}{ Han nationality } & $-0.709 * * *$ & $-0.515^{* * *}$ & -0.110 & $-0.241^{*}$ \\
\hline & $(0.056)$ & $(0.053)$ & $(0.151)$ & $(0.137)$ \\
\hline \multirow{2}{*}{ Sex (male is 1 and female is 0 ) } & $-0.099 * *$ & -0.053 & -0.077 & 0.056 \\
\hline & $(0.046)$ & $(0.046)$ & $(0.103)$ & $(0.096)$ \\
\hline \multirow{2}{*}{ Father's educated term } & $0.034 * * *$ & $0.037 * * *$ & 0.004 & 0.012 \\
\hline & $(0.006)$ & $(0.006)$ & $(0.014)$ & $(0.013)$ \\
\hline \multirow{2}{*}{ Mother's educated term } & $0.039 * * *$ & $0.014 * *$ & 0.003 & -0.020 \\
\hline & $(0.007)$ & $(0.007)$ & $(0.013)$ & $(0.013)$ \\
\hline \multirow{2}{*}{$\begin{array}{l}\text { Parents' nonagricultural income is in the low } \\
\text { group }\end{array}$} & $-0.185 * *$ & -0.085 & 0.141 & -0.073 \\
\hline & $(0.083)$ & $(0.081)$ & $(0.220)$ & $(0.204)$ \\
\hline \multirow{2}{*}{$\begin{array}{l}\text { Parents' nonagricultural income is in the } \\
\text { middle group }\end{array}$} & -0.096 & 0.040 & $0.312 *$ & 0.114 \\
\hline & $(0.086)$ & $(0.087)$ & $(0.171)$ & $(0.166)$ \\
\hline \multirow{2}{*}{$\begin{array}{l}\text { Parents' nonagricultural income is in the } \\
\text { high group }\end{array}$} & $0.359 * * *$ & $0.459 * * *$ & 0.123 & -0.060 \\
\hline & $(0.089)$ & $(0.095)$ & $(0.163)$ & $(0.154)$ \\
\hline \multirow{2}{*}{ Father's occupation is farmer } & $-0.163 * * *$ & 0.026 & 0.026 & -0.003 \\
\hline & $(0.050)$ & $(0.050)$ & $(0.111)$ & $(0.101)$ \\
\hline \multirow{2}{*}{$\begin{array}{l}\text { Father's occupation is in the class of } \\
\text { management and technology }\end{array}$} & $0.467 * * *$ & $0.488 * * *$ & 0.292 & -0.070 \\
\hline & $(0.124)$ & $(0.137)$ & $(0.197)$ & $(0.191)$ \\
\hline \multirow{2}{*}{ Scale of family children } & -0.014 & $-0.065 * * *$ & -0.030 & $-0.119 * *$ \\
\hline & $(0.024)$ & $(0.024)$ & $(0.057)$ & $(0.053)$ \\
\hline \multirow{2}{*}{$\begin{array}{l}\text { Parents do works for others far from } \\
\text { hometown }\end{array}$} & 0.111 & 0.287 & 0.258 & 0.316 \\
\hline & $(0.182)$ & $(0.187)$ & $(0.421)$ & $(0.402)$ \\
\hline \multirow{2}{*}{$\begin{array}{l}\text { Whether there are long-term sickened } \\
\text { members in the family }\end{array}$} & & $-0.163 * * *$ & & $-0.247 * *$ \\
\hline & & $(0.041)$ & & $(0.125)$ \\
\hline \multirow[t]{2}{*}{ Opportunity of provincial higher education } & & $0.003 * * *$ & & 0.003 \\
\hline & & $(0.001)$ & & $(0.002)$ \\
\hline \multirow{2}{*}{ Item of constant } & $-0.237 * * *$ & -0.044 & -0.673 & 0.107 \\
\hline & $(0.084)$ & $(0.109)$ & $(0.185)$ & $(0.233)$ \\
\hline \multirow{2}{*}{ Inverse Mill's ration } & 7.106 & & 5.800 & \\
\hline & $(84.086)$ & & $(81.169)$ & \\
\hline Value of maximum likelihood function & -3658.080 & & -899.442 & \\
\hline Observation point & 3800 & & 865 & \\
\hline
\end{tabular}

Note: $* * *$ and $* * *$ respectively denote the significance levels of $10 \%, 5 \%$ and $1 \%$. 
Table 4. Comparison of the educational demand-identified bivariate probit model estimation and the single-variable probit model estimation

\begin{tabular}{|c|c|c|c|c|c|c|}
\hline & \multicolumn{3}{|c|}{$\begin{array}{l}\text { Stage from junior high school to senior } \\
\text { high school }\end{array}$} & \multicolumn{3}{|c|}{ Stage from senior high school to college } \\
\hline & \multicolumn{2}{|c|}{$\begin{array}{c}\text { Bivariate probit } \\
\text { model }\end{array}$} & \multirow{2}{*}{$\begin{array}{l}\text { Single-variable } \\
\text { probit model }\end{array}$} & \multicolumn{2}{|c|}{$\begin{array}{c}\text { Bivariate probit } \\
\text { model }\end{array}$} & \multirow{2}{*}{$\begin{array}{l}\text { Single-variable } \\
\text { probit model }\end{array}$} \\
\hline & $\begin{array}{l}\text { Supply } \\
\text { equation }\end{array}$ & $\begin{array}{l}\text { Demand } \\
\text { equation }\end{array}$ & & $\begin{array}{l}\text { Supply } \\
\text { equation }\end{array}$ & $\begin{array}{l}\text { Demand } \\
\text { equation }\end{array}$ & \\
\hline Han nationality & - & - & - & & - & \\
\hline Sex & - & & - & & & \\
\hline Father's educated term & + & + & + & & & \\
\hline $\begin{array}{l}\text { Mother's educated } \\
\text { term }\end{array}$ & + & + & + & & & \\
\hline $\begin{array}{l}\text { Parents' } \\
\text { nonagricultural income } \\
\text { is in the low group }\end{array}$ & - & & - & & & \\
\hline $\begin{array}{l}\text { Parents' } \\
\text { nonagricultural income } \\
\text { is in the middle group }\end{array}$ & + & + & + & + & & \\
\hline $\begin{array}{l}\text { Parents' } \\
\text { nonagricultural income } \\
\text { is in the high group }\end{array}$ & & & & & & \\
\hline $\begin{array}{l}\text { Father's occupation is } \\
\text { farmer }\end{array}$ & - & & - & & & \\
\hline $\begin{array}{l}\text { Father's occupation is } \\
\text { in the class of } \\
\text { management and } \\
\text { technology }\end{array}$ & + & + & + & & & \\
\hline $\begin{array}{l}\text { Scale of family } \\
\text { children }\end{array}$ & & - & & & - & \\
\hline $\begin{array}{l}\text { Parents do works for } \\
\text { others far from } \\
\text { hometown }\end{array}$ & & & & & & \\
\hline $\begin{array}{l}\text { Whether there are } \\
\text { long-term sickened } \\
\text { members in the family }\end{array}$ & / & - & & / & - & \\
\hline $\begin{array}{l}\text { Opportunity of } \\
\text { provincial higher } \\
\text { education }\end{array}$ & / & + & & / & & + \\
\hline
\end{tabular}

Note: + and - respectively denote the positive relationship and the negative relationship above $10 \%$ significant level, and the blank denotes the insignificance, and / denotes that the model setup doesn't include this variable. 


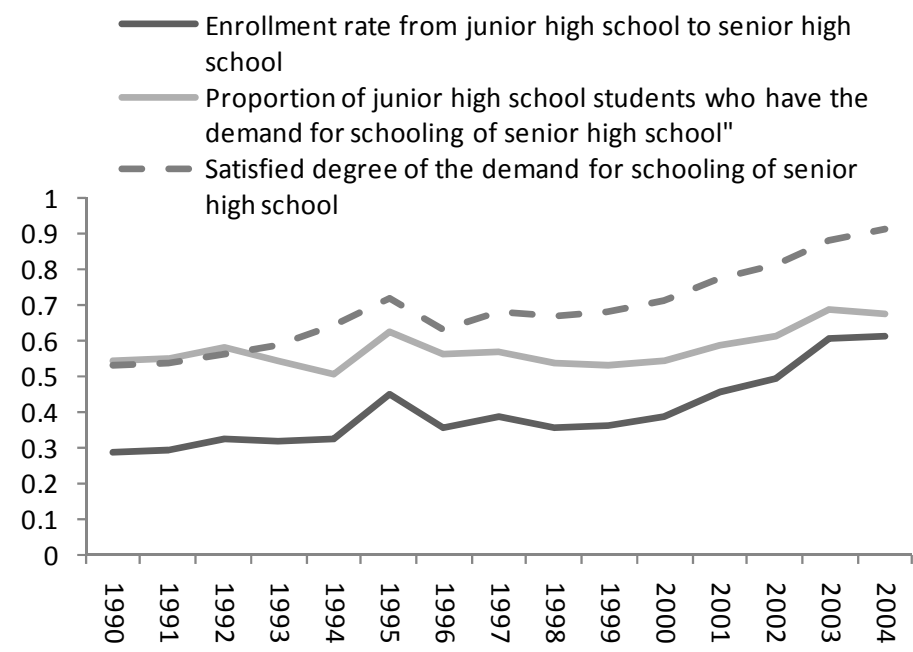

Enrollment rate from senior high school to college

Proportion of senior high school students who have the demand for schooling of college

- Satisfied degree of the demand for schooling of college

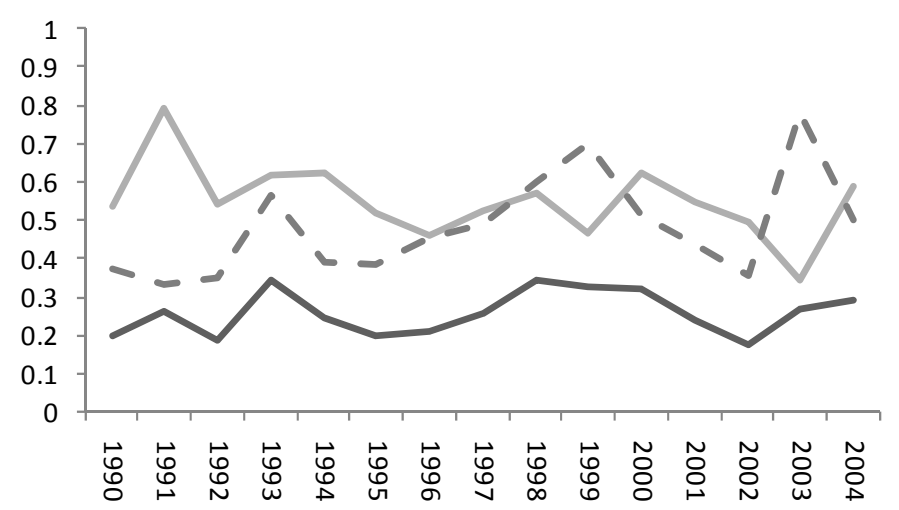

Figure 1. Time-sequence characters of the demand for schooling and its satisfied state 